\title{
Lifestyle breast cancer patients among Indonesian women: A nationwide survey
}

\author{
Solikhah Solikhah ${ }^{1}$, Khairunnisaa Nuur Aliifah Setyawati ${ }^{2}$, Monthida Sangruangake ${ }^{3}$ \\ ${ }^{1,2}$ Faculty of Public Health, Universitas Ahmad Dahlan, Yogyakarta, Indonesia \\ ${ }^{3}$ Faculty of Nursing, Khon Kaen University, Thailand
}

\begin{tabular}{l} 
Article Info \\
\hline Article history: \\
Received Feb 26, 2021 \\
Revised Aug 8, 2021 \\
Accepted Aug 24, 2021 \\
\hline
\end{tabular}

Keywords:

Breast cancer

Indonesia

Lifestyle

Physical activity

Smoking

\begin{abstract}
Recently, cancer is a major health problem in the world. Lifestyle changes and growing urbanization likely led to increasing breast cancer incidence in such in Indonesia. Therefore, this study aimed to explore lifestyle breast cancer patients among Indonesian women. The investigation was a crosssectional study distributed among 3,392 females drawn from 13 out of 27 provinces in Indonesia. Multiple binary logistic regressions were conducted to investigate breast cancer risk among Indonesian. A significance level of 0.05 was employed in all analysis. Of the 3,392 respondents included in the analysis, more than half $(52.71 \% ; \mathrm{n}=1,788)$ was aged $40-49$ years old. The most common marital status of the participants was married $(98.20 \%$; $\mathrm{n}=3,331)$, followed by no smoking $(94.69 \% ; \mathrm{n}=3,212)$ and active exercise $(62.12 \% ; n=2,107)$. Education level was significantly associated with breast cancer (AdjOR_Junior high school $=0.21 ; 95 \% \mathrm{CI}=0.06$ to $0.70 ; \mathrm{p}<0.01$ and AdjOR_senior high school $=0.60 ; 95 \% \mathrm{CI}=0.15$ to 2.26 ; $\mathrm{p}<0.05$ ). Education level was significantly related to breast cancer. Lifestyle such as smoking and physical activity was suspected to affect breast cancer indirectly.
\end{abstract}

This is an open access article under the CC BY-SA license.

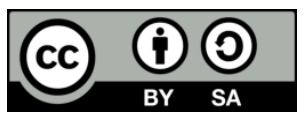

\section{Corresponding Author:}

Solikhah Solikhah

Faculty of Public Health

Universitas Ahmad Dahlan

Yogyakarta 55164, Indonesia

Email: solikhah@ikm.uad.ac.id

\section{INTRODUCTION}

Recently, cancer is a major problem globally, both in developed and developing countries and is most often found in women. Globally, breast cancer ranks second as the leading cause of death worldwide (11.6\%) after lung cancer [1]. Among Southeast Asian countries, the highest incidence of breast cancer was in Indonesia 48,998 cases, which was then followed by the Philippines 18,327 cases, Thailand 13,653 cases, and Vietnam 11,067 cases [2]. The mortality rate from breast cancer is $35.5 \%$ of the 107,545 incidences of breast cancer in Southeast Asia [2].

The leading cause of breast cancer remains unknown, but it can be avoided by increasing knowledge about its risk factors. Several previous studies revealed that breast cancer risk factors could be divided into two factors that cannot be controlled, such as age [3]-[5] and gender [6]. Also, several factors can be controlled, such as physical activity [7], [8]; employment [9], [10]; knowledge of signs and symptoms of breast cancer [11] and smoking [12]. Meanwhile, Indonesia as the fourth most populous country globally remains ignorant of a healthy lifestyle with many people who lack exercise, smoking, high consumption of fast food, and less attention to balanced nutrition. Moreover, the government has no priority to provide mass breast cancer screening as a national program that led to most patients with breast cancer diagnosed in the 
advanced stage. Also, public awareness to seek health care services is low due to lack of knowledge of breast cancer signs and symptoms [11]. Therefore, exploring lifestyle using the Indonesian family life survey (IFLS) data is needed for evaluating the community's lifestyle. IFLS-5 is one of big data sources of data from a longitudinal survey conducted in Indonesia that covered $80 \%$ of the total across the province and conducted every seven years that included many variables related to individual characteristics, the environment, and health care facilities.

\section{RESEARCH METHOD}

\subsection{Sample and data collection}

A secondary analysis of data collected by RAND and Survey Metter (https://www.rand.org/wellbeing/social-and-behavioral-policy/data/FLS/IFLS/ifls5.html) was used in this study. We used data in IFLS wave five conducted in this research. The sample size was taken as many as 3,392 females, drawn from 13 out of 27 provinces in Indonesia. The inclusion criteria were willing to participate and involved in the next phase of the study and aged $\geq 40$ years. Missing data were excluded. A structured questionnaire was provided to respondents and taken by IFLS- wave 5.

All data in this study were obtained from four types of questionnaire books in the Household Survey Questionnaire Book, which can be assessed https://www.rand.org/well-being/social-and-behavioralpolicy/data/FLS/IFLS/download.html. Based on IFLS-5 data, the variable of breast cancer was assessed using a mammogram by a medical doctor in oncology. Then, subjects were classified into the two categories of Yes and No based on the IFLS-5 data. Physical activity measured within seven days. Physical activity is classified into two categories namely "active", and "inactive", The category of "active" if the respondent met one of two criteria: i) physical activity is carried out with high intensity for at least three days and reached a total activity of at least 1500 MET-minutes/week, or; ii) A combination of walking activity at least seven days with moderate - vigorous intensity and achieve a total activity of at least 3000 MET-minutes/week; iii) high-intensity activity for minimum three days at least 20 minutes per day; iv) moderate-intensity activity for minimum five days and or/at least 30 minutes of walking activity per days; v) a combination of moderate-high intensity walking activity and the total activity of 600 MET-minutes/week. The category of "inactive" if the respondent carries out physical activity but is not included in the category of "active". Smoking is measured using a dichotomy nominal (Yes=if respondent chewed tobacco or smoking during the study or in the past; No= if the respondent did not chew tobacco or smoking during the study or past). Several demographic characteristics of participants were also measured, such as age, marital status, education level and occupation.

\subsection{Ethical clearance}

Approvals for this study were obtained from Universitas Ahmad Dahlan Ethics Committee for Health Research that Uses Humans as Research Subjects (Number: 011905053).

\subsection{Data analysis}

Sociodemographic data of participants were presented by the frequency and percentage of a categorical variable and mean following with standard deviation for continuous data. Statistical test using logistic regression was conducted to examine factors' influence on breast cancer risk. All analysis was performed using STATA version 15.0. A significance level of 0.05 was employed in all analysis.

\section{RESULTS AND DISCUSSION}

\subsection{Results}

Of the 3,392 respondents included in the analysis, more than half $(52.71 \% ; \mathrm{n}=1,788)$ was aged 40 49 years old. The most common marital status of the participants was married $(98.20 \% ; n=3,331)$, followed by no smoking $(94.69 \% ; n=3,212)$ and active exercise $(62.12 \% ; n=2,107)$. The demographic characteristics of the participants are presented in Table 1.

The correlation of sociodemographic participants with breast cancer incidence are presented in Table 2. Women with low educational levels in Junior high school were significantly associated with lower breast cancer incidence $(\mathrm{OR}=0.31 ; 95 \% \mathrm{CI}=0.07$ to $0.77 ; \mathrm{p}<0.05)$. Then, a multivariate binary logistic regression was used to evaluate the predictors of breast cancer incidence. The result of this study showed significant relationship between education level (elementary school) and breast cancer (AdjOR_Junior high school=0.21; $95 \% \mathrm{CI}=0.06$ to $0.70 ; \mathrm{p}<0.01$ and AdjOR_senior high school=0.60; $95 \% \mathrm{CI}=0.15$ to 2.26; $\mathrm{p}<0.05)$. However, there were no significant associations with age, marital status, occupation, physical activity, and smoking. 
Table 1. Demographic characteristics of respondents

\begin{tabular}{lcc}
\hline \multicolumn{1}{c}{ Items } & $\mathrm{n}=3,392$ & Percentage (\%) \\
\hline Breast cancer & & \\
$\quad$ Yes & 20 & 0.59 \\
$\quad$ No & 3,372 & 99.41 \\
Age (years old) & 1,788 & 52.71 \\
$\quad 40-49$ & 1,103 & 32.52 \\
$50-59$ & 501 & 14.77 \\
$\geq 60$ & & \\
Marital status & 61 & 1.80 \\
$\quad$ Unmarried & 3,331 & 98.20 \\
$\quad$ Married & & \\
Education level & 1,042 & 30.72 \\
$\quad$ Elementary school & 1,629 & 48.02 \\
$\quad$ Junior high school & 401 & 11.82 \\
$\quad$ Senior high school & 320 & 9.43 \\
$\quad$ Higher education & & \\
Occupation & 1,639 & 0.13 \\
$\quad$ Housewife & 1,639 & 51.21 \\
$\quad$ Civil servant/private sector/entrepreneurs & & \\
Physical activity & 1,285 & 37.88 \\
$\quad$ Inactive & 2,107 & 62.12 \\
$\quad$ Active & & \\
Smoking & 180 & 5.31 \\
$\quad$ Yes & 3,212 & 94.69 \\
$\quad$ No & & \\
\hline
\end{tabular}

Table 2. Adjusted ORs and 95\% CI of a risk factor for breast cancer

\begin{tabular}{|c|c|c|c|c|}
\hline Items & Crude OR & $95 \% \mathrm{CI}$ & Adjusted OR & $95 \% \mathrm{CI}$ \\
\hline \multicolumn{5}{|l|}{ Age (ref: 40-49 years old) } \\
\hline $50-59$ & 1.63 & $0.64-4.11$ & 1.86 & $0.73-4.80$ \\
\hline$\geq 60$ & 0.79 & $0.17-3.68$ & 0.90 & $0.19-4.25$ \\
\hline \multicolumn{5}{|l|}{ Marital status (ref: married) } \\
\hline Unmarried & 2.90 & $0.38-22.06$ & 2.47 & $0.32-19.25$ \\
\hline \multicolumn{5}{|l|}{ Education level (ref: higher education) } \\
\hline Elementary school & 0.31 & $0.09-1.06$ & 0.28 & $0.08-0.98$ \\
\hline Junior high school & 0.31 & $0.07-0.77^{*}$ & 0.21 & $0.06-0.70 * *$ \\
\hline Senior high school & 0.31 & $0.17-2.38$ & 0.60 & $0.15-2.26^{*}$ \\
\hline \multicolumn{5}{|l|}{ Occupation (ref: housewife) } \\
\hline Civil servant/Private sector/entrepreneur & 1.41 & $0.57-3.45$ & 1.71 & $0.68-4.31$ \\
\hline \multicolumn{5}{|l|}{ Physical activity (ref: active) } \\
\hline Inactive & 0.75 & $0.31-1.80$ & 0.75 & $0.31-1.81$ \\
\hline \multicolumn{5}{|l|}{ Smoking (ref: No smoking) } \\
\hline Smoking & 0.94 & $0.12-7.05$ & 0.95 & $0.13-7.20$ \\
\hline
\end{tabular}

\subsection{Discussion}

Breast cancer is a malignant tumour that develops in the breast. If the cells in the mammary gland divide uncontrollably, they will become benign or malignant tumours [13]. Having breast cancer or receiving treatment, most patients with breast cancer have been experienced depression, anxiety and fear. The emotional problems can also arise after cancer treatments such as worry if it might return [14]. Other issues are also found for patients and families, such as the high cost of breast cancer treatment [15]. Increasing knowledge of breast cancer risk factors is needed as an effort to reduce the number of breast cancer cases, especially for low-middle income countries such as Indonesia. Age is well known as a risk factor for breast cancer that uncontrolled [3]-[5]; and gender [6]. Meanwhile, several factors can be modified to reduce the high prevalence of breast cancer, such as physical activity [7], [8]; occupation [9], [10]; and adopted lifestyle including smoking, high stress, obesity and high-fat food [12].

The findings showed that women with elementary school and junior high school were significantly associated with breast cancer. Educational level is known to relate to the knowledge and attitudes of breast cancer [16]. In line with the previous study, the lower educational level had lack of awareness and financial limitations to check their breast as early as possible when they felt something abnormal in their breast (e.g. pain, swelling, and nipple discharge) [17]. The low educational level among participants of this study affected their inadequate understanding of early signs and symptoms of a disease and early prevention efforts of the disease, including their lack of knowledge for early breast cancer screening. In addition, women feel 
frightened abandoned by their spouse if they had breast cancer [18]. Meanwhile, higher education had a greater chance of being diagnosed with early-stage breast cancer [19].

This study also revealed that this result of this study inverse for married women. This is due to women who married and breastfed their children had a lower risk of breast cancer because they had fewer menstrual cycles to be exposed to shorter estrogen where estrogen triggers breast cancer [20]-[22]. This finding also reported that lifestyle such as physical activity had not significantly related to breast cancer. However, regular physical activity can reduce the risk of breast cancer [23]. Physical activity was associated with low body fat and low levels of all hormones that affect breast cancer and will be able to improve immune function [24]-[26] and decrease hormonal circulation to reduce the proliferation process and prevent breast cancer events [7]. The more prolonged heavy physical activity routinely carried out it can reduce the risk of breast cancer. The same pattern was found in this study for the smoking variable. Smoking affected increasing the risk of breast cancer because cigarette smoke/tobacco smoke contains high concentrations of Acetaldehyde which can be absorbed entirely in breast tissue and were found in breast milk. Acetaldehyde is a carcinogen that can cause cancer [12]. The risk of breast cancer is higher in women who are active smokers, but our respondents who did not smoke tended to be smaller due to smoking habits in women in Indonesia unlike in Western countries [27]-[30].

Some strength should be acknowledged. This study was conducted thoroughly in Indonesia with involved almost $80 \%$ of the total population. This study used a large sample that was spread across 13 provinces in Indonesia so that it represented Indonesia both economically and socio-culturally. However, this study's weakness noted that this study used secondary data so that it can only retrieve data following established inclusion criteria. In addition, the design used in this study was cross-sectional, where the design was not too robust for causal analysis, because it could not determine whether the cause precedes the effect. In addition, only a small number of participants incidence diagnosed with breast cancer in this study. The participants completed questionnaire in this study were all female, mostly married, and a had low-level education. As a consequence, selection bias may, in some way affect the generalizability of the findings since women and person with low-level education generally did not aware of breast cancer signs and symptoms. Consequently, the actual lifestyle of breast cancer patients in the population is most probably higher than estimated here.

\section{CONCLUSION}

Lifestyles such as smoking and physical activity were suspected to affect breast cancer indirectly; however, comparing breast cancer patients between healthy and unhealthy lifestyles needs to be proven future. Lifestyles such as smoking and physical activity were suspected to affect breast cancer indirectly; however, comparing breast cancer patients between healthy and unhealthy lifestyles needs to be proven future. Changes lifestyle such as quitting smoking, active exercise, reducing alcohol consumption, taking vitamin and minerals seem an effective, easy, and economical ways to help prevention of breast cancer.

\section{ACKNOWLEDGEMENTS}

This study was supported by the fifth wave of the Indonesian Family Life Survey (IFLS-5) conducted by RAND and Survey Meter (https://www.rand.org/well-being/social-and-behavioralpolicy/data/FLS/IFLS/ifls5.html). Authors thank RAND for providing permission to use the survey data and the study participants who provided the survey data. “66

\section{REFERENCES}

[1] F. Bray, J. Ferlay, I. Soerjomataram, RL. Siegel, LA. Torre, and A. Jemal, "Global cancer statistics 2018: GLOBOCAN estimates of incidence and mortality worldwide for 36 cancers in 185 countries," CA: A Cancer Journal for Clinicians, vol. 68, no. 6, pp. 394-424, 2018, doi: 10.3322/caac.21492.

[2] Y. Kim, K-Y. Yoo, and MT. Goodman, "Differences in incidence, mortality and survival of breast cancer by regions and countries in Asia and contributing factors," Asian Pac J Cancer Prev. vol. 16, no. 7, pp. 2857-2870, 2015, doi: 10.7314/apjcp.2015.16.7.2857.

[3] Y-S. Sun et al., "Risk Factors and Preventions of Breast Cancer," Int J Biol Sci., vol. 13, no. 11, pp. 1387-97, 2017, doi: 10.7150/ijbs.21635.

[4] RL. Siegel, KD. Miller, and A. Jemal, “Cancer Statistics, 2017,” CA Cancer J. Clin., vol. 67, no. 1, pp. 7-30. 2017, $10.3322 /$ caac. 21387.

[5] E.W. Hofstatter et al., "Increased epigenetic age in normal breast tissue from luminal breast cancer patients," Clin Epigenetics., vol. 10, no. 1, pp. 1-11. 2018, doi: 10.1186/s13148-018-0534-8.

[6] Z. Kleibl and VN. Kristensen, "Women at high risk of breast cancer: Molecular characteristics, clinical presentation and management," Breast., vol. 28, pp. 136-144, 2016, doi: 10.1016/j.breast.2016.05.006.

Lifestyle breast cancer patients among Indonesian women: A nationwide survey (Solikhah Solikhah) 
[7] M-E. Spei, E. Samoli, F. Bravi, C. La Vecchia, C. Bamia, V. Benetou, "Physical activity in breast cancer survivors: A systematic review and meta-analysis on overall and breast cancer survival," The Breast, vol. 44, pp. 144-52, 2019, doi: 10.1016/j.breast.2019.02.001.

[8] HH. Kyu et al., "Physical activity and risk of breast cancer, colon cancer, diabetes, ischemic heart disease, and ischemic stroke events: systematic review and dose-response meta-analysis for the Global Burden of Disease Study 2013," BMJ, vol. 354, 2016, doi: 10.1136/bmj.i3857.

[9] RC. Travis et al., "Night Shift Work and Breast Cancer Incidence: Three Prospective Studies and Meta-analysis of Published Studie," J Natl Cancer Inst., vol. 108, no. 12, pp. 1-9, 2016, doi: 10.1093/jnci/djw169.

[10] T. Åkerstedt, A. Knutsson, J. Narusyte, P. Svedberg, G. Kecklund, and K. Alexanderson, "Night work and breast cancer in women: a Swedish cohort study," BMJ Open, vol. 5, no. 4, pp. 1-6, 2015, doi: 10.1136/bmjopen-2015008127.

[11] S. Solikhah, S. Promthet, and C. Hurst, "Awareness Level about Breast Cancer Risk Factors, Barriers, Attitude and Breast Cancer Screening among Indonesian Women," Asian Pac J Cancer Prev., vol. 20, no. 3, pp. 877-884, 2019, doi: 10.31557/APJCP.2019.20.3.877.

[12] W. Duan, S. Li, X. Meng, Y. Sun, and C. Jia, "Smoking and survival of breast cancer patients: A meta-analysis of cohort studies," The Breast, vol. 33, pp. 117-24, 2017, doi: 10.1016/j.breast.2017.03.012.

[13] Z. Tao, A. Shi, C. Lu, T. Song, Z. Zhang, and J. Zhao, "Breast Cancer: Epidemiology and Etiology," Cell Biochem Biophys, vol. 72, no. 2, pp. 333-338, 2015, doi: 10.1007/s12013-014-0459-6.

[14] RR. Reich et al., "Mindfulness-Based Stress Reduction in Post-treatment Breast Cancer Patients: Immediate and Sustained Effects across Multiple Symptom Clusters," Journal of Pain and Symptom Management. vol. 53, no. 1, pp. 85-95, 2017, doi: 10.1016/j.jpainsymman.2016.08.005.

[15] R. Daroudi, A. Akbari Sari, A. Nahvijou, B. Kalaghchi, M. Najafi, and K. Zendehdel, "The economic burden of breast cancer in Iran," Iran J Public Health. vol. 44, no. 9, pp. 1225-1233, 2015.

[16] JR. Scheel et al., "Breast Cancer Beliefs as Potential Targets for Breast Cancer Awareness Efforts to Decrease Late-Stage Presentation in Uganda," J Glob Oncol., vol. 4, pp. 1-9, 2018, doi: 10.1200/JGO.2016.008748.

[17] L. Hvidberg et al., "Cancer awareness and socio-economic position: results from a population-based study in Denmark," BMC Cancer, vol. 14, no. 581, pp. 1-13, 2014, doi: 10.1186/1471-2407-14-581.

[18] S. Solikhah et al., "Breast cancer stigma among Indonesian women: a case study of breast cancer patients," BMC Womens Health, vol. 20, no. 116, pp. 1-5, 2020, doi: 10.1186/s12905-020-00983-x.

[19] SM. Phillips, KW. Dodd, J. Steeves, J. McClain, CM. Alfano, and E. McAuley, "Physical Activity and Sedentary Behavior in Breast Cancer Survivors: New Insight into Activity Patterns and Potential Intervention Targets," Gynecol Oncol. vol. 138, no. 2, pp. 398-404, 2015, doi: 10.1016/j.ygyno.2015.05.026.

[20] L. Hinyard, LS. Wirth, JM. Clancy, T. Schwartz, "The effect of marital status on breast cancer-related outcomes in women under 65: A SEER database analysis,” Breast. vol. 32, pp. 13-17, 2017, doi: 10.1016/j.breast.2016.12.008.

[21] Babita null, N. Kumar, M. Singh, JS. Malik, M. Kalhan, "Breastfeeding reduces breast cancer risk: a case-control study in north India," Int J Prev Med. vol. 5, no. 6, pp. 791-795, 2014.

[22] M. E. Martínez, "Prognostic significance of marital status in breast cancer survival: A population-based study," PLoS One, vol. 12, no. 5, pp. 1-14, 2017, doi: 10.1371/journal.pone.0175515.

[23] K Rojas and A. Stuckey, "Breast Cancer Epidemiology and Risk Factors," Clin Obstet Gynecol., vol. 59, no. 4, pp. 651-672, 2016, doi: 10.1097/GRF.0000000000000239.

[24] Z. Gong et al., "Vigorous physical activity and risk of breast cancer in the African American breast cancer epidemiology and risk consortium," Breast Cancer Res Treat., vol. 159, no. 2, pp. 347-356, 2016, doi: 10.1007/s10549-016-3936-3.

[25] J. Kerr, C. Anderson, and SM. Lippman, "Physical activity, sedentary behaviour, diet, and cancer: an update and emerging new evidence," Lancet Oncol, vol. 18, pp. e457-e471, 2017, doi: 10.1016/S1470-2045(17)30411-4.

[26] JA. Ligibel, K. Basen-Engquist, JW. Bea, "Weight Management and Physical Activity for Breast Cancer Prevention and Control," Am Soc Clin Oncol Educ Book, vol. 39, pp. e22-e33, 2019, doi: 10.1200/EDBK_237423.

[27] S. Kispert and J. McHowat, "Recent insights into cigarette smoking as a lifestyle risk factor for breast cancer," Breast Cancer (Dove Med Press), vol. 9, pp. 127-132, 2017, doi: 10.2147/BCTT.S129746.

[28] A. Macacu et al., "Active and passive smoking and risk of breast cancer: a meta-analysis," Breast Cancer Res Treat, vol. 154, no. 2, pp. 213-224, 2015, doi: 10.1007/s10549-015-3628-4.

[29] C. Catsburg, AB. Miller, and TE. Rohan, "Active cigarette smoking and risk of breast cancer," Int J Cancer, vol. 136, no. 9, pp. 2204-2209, 2015, doi: 10.1002/ijc.29266.

[30] M. M. Gaudet et al., "Pooled analysis of active cigarette smoking and invasive breast cancer risk in 14 cohort studies," Int J Epidemiol., vol. 46, no. 3, pp. 881-93, 2017, doi: 10.1093/ije/dyw288. 